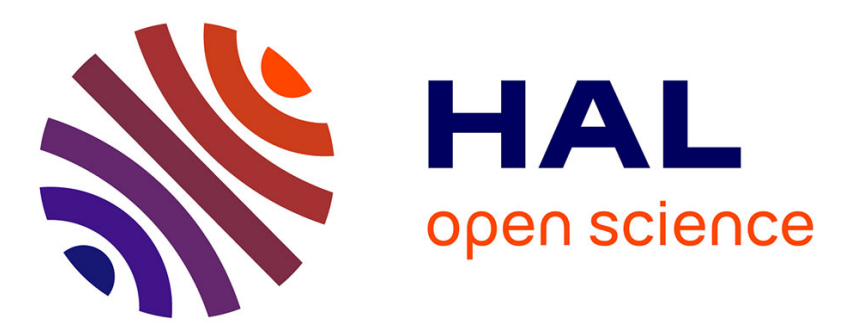

\title{
Experimental measurement of temperature distribution in the chip generated during high speed orthogonal cutting process
}

\author{
Guy Sutter, Nicolas Ranc, Alain Molinari, Vincent Pina
}

\section{- To cite this version:}

Guy Sutter, Nicolas Ranc, Alain Molinari, Vincent Pina. Experimental measurement of temperature distribution in the chip generated during high speed orthogonal cutting process. International Journal of Machining and Machinability of Materials, 2008, 3 (1-2), pp.52-61. 10.1504/IJMMM.2008.017624 . hal-00283633

\section{HAL Id: hal-00283633 \\ https://hal.science/hal-00283633}

Submitted on 13 Mar 2018

HAL is a multi-disciplinary open access archive for the deposit and dissemination of scientific research documents, whether they are published or not. The documents may come from teaching and research institutions in France or abroad, or from public or private research centers.
L'archive ouverte pluridisciplinaire HAL, est destinée au dépôt et à la diffusion de documents scientifiques de niveau recherche, publiés ou non, émanant des établissements d'enseignement et de recherche français ou étrangers, des laboratoires publics ou privés. 


\title{
Experimental measurement of temperature distribution in the chip generated during high speed orthogonal cutting process
}

\section{Guy Sutter}

LPMM, ISGMP,

Université Paul Verlaine de METZ, Ile du SAULCY,

Metz Cedex 01 57045, France Fax: +33-03-87-31-53-66

E-mail: sutter@lpmm.univ-metz.fr

\section{Nicolas Ranc}

LEEE E.A. 387,

Université de Paris X, Nanterre,

1 , chemin Desvallières,

Ville d'avray 92410, France

E-mail: nicolas.ranc@cva.u-paris10.fr

\author{
Alain Molinari \\ LPMM, ISGMP, \\ Université Paul Verlaine de METZ, Ile du SAULCY, \\ Metz Cedex 01 57045, France \\ Fax: +33-03-87-31-53-66 \\ E-mail: molinari@lpmm.univ-metz.fr

\section{Vincent Pina} \\ IUT de Ville d'avray - GTE, Université Paris X, \\ 50 rue de Sèvres, \\ Ville d'avray 92410, France Fax: +33-01-47-09-45-68 \\ E-mail: vincent.pina@u-paris10.fr
}

\begin{abstract}
Temperature field measurements in the chip are performed during high speed machining of a low carbon steel (XC18) and a medium carbon steel (42CrMo4). An original mechanical device based on the propelling of a projectile by decompression of air allows to investigate a wide range of cutting speeds from 10 to $120 \mathrm{~m} / \mathrm{s}$. The technique of temperature measurement using the principle of pyrometry in the visible spectral range is realised with an intensified CCD camera with a very short exposure time. Temperature maps presented for the two steels confirm that the heating in the chip is not uniform and the presence of a maximal temperature area. The effects of cutting parameters such as chip thickness and cutting velocity are presented.
\end{abstract}

Keywords: chip temperature distribution; high speed machining; chip geometry; experimental measurement; orthogonal cutting process. 


\section{Introduction}

To understand the physical phenomena generated during cutting processes, the characterisation of the temperature field is essential. The most important part of the work generated during the cutting process is converted into heat (Barrow, 1973). There are three main regions concerned with heating during the cutting process: the primary shear zone where the chip is formed, is characterised by high shear deformation. The secondary and the tertiary zone where friction and shearing are combined, are located respectively along the tool-chip interface and below the tool edge. In these regions heat is generated and flows into the workpiece, the chip and the tool. The temperature is an important parameter controlling to tool wear and consequently the life duration, the quality of the surface finish, chip segmentation and the choice of lubrication. Furthermore, thermal aspects become more important with high cutting speeds used presently in industrial processes. A large number of techniques (Komanduri and Hou, 2001) have been developed to quantify the temperature, which can be classified as intrusive (e.g. thermocouple technique (El-Wardany et al., 1996; O'Sullivan and Cotterell, 2001)) or non-intrusive techniques (e.g. pyrometry technique (Muller and Renz, 2003; Outeiro et al., 2004; Ranc et al., 2000; Sutter et al., 2003).

Pyrometry techniques are often used to study the mechanical behaviour of material because they have many advantages compared to the thermocouple techniques (Pina et al., 2004). Firstly, this is a non-intrusive technique, which does not disturb the temperature measurement; secondly, the response time can be as short as few nanoseconds. Finally, the spatial resolution, which is only limited by the diffraction phenomenon, can be of the order of few micrometres.

To study high speed machining, we have developed a high speed broad band visible pyrometer using an intensified CCD camera (spectral range: 0.4-0.9 $\mu \mathrm{m}$ ) (Ranc et al., 2004; Sutter et al., 2003). The cutting process is realised with an original ballistic set-up, which allows to reach very high cutting speeds $\left(V_{\max } \approx 120 \mathrm{~m} / \mathrm{s}\right.$ ), without parasite vibrations usually found in industrial machines. The influence on the temperature distribution of the cutting speed and of the depth of cut are analysed in detail. Contrary to previous results concerning medium carbon steel (Sutter et al., 2003) no maximum value of temperature seems to be reached as the cutting speed increases.

The performances of our measurement set up can also be illustrated by the possibility of recording real time photographs of the chip formation in high speed machining. These photographs are useful to define precisely the chip morphology and the contact length at the tool-chip interface.

\section{Experimental device}

\subsection{Mechanical part}

A high speed experimental set-up (Sutter et al., 2005), shown in Figure 1, has been designed to study cutting processes. The workpiece is fixed on a projectile, which is propelled in a launch tube by the release of compressed air. A receiving tube supports the cutting tools and guides the projectile and the specimen toward a shock absorber. Speed and acceleration are controlled with a set of photo-diodes and time counters. 
Figure 1 Experimental ballistic set-up employed to reproduce high speed orthogonal cutting conditions

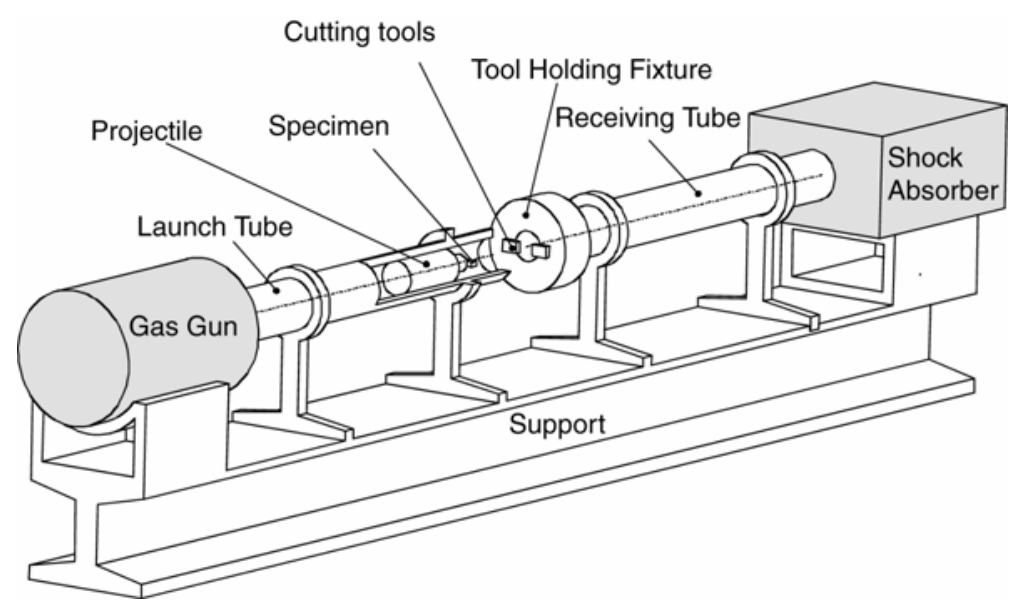

Perfect orthogonal cutting conditions are obtained with this ballistic set-up and a good accessibility allows introducing an intensified CCD camera and visualising the chip formation (see Figure 2). To limit outside brilliance and collect chips for post-mortem analysis, all the cutting process is carried out in a black box.

Figure 2 Schematic representation of the thermal measurement system and details of the recorded cutting zone

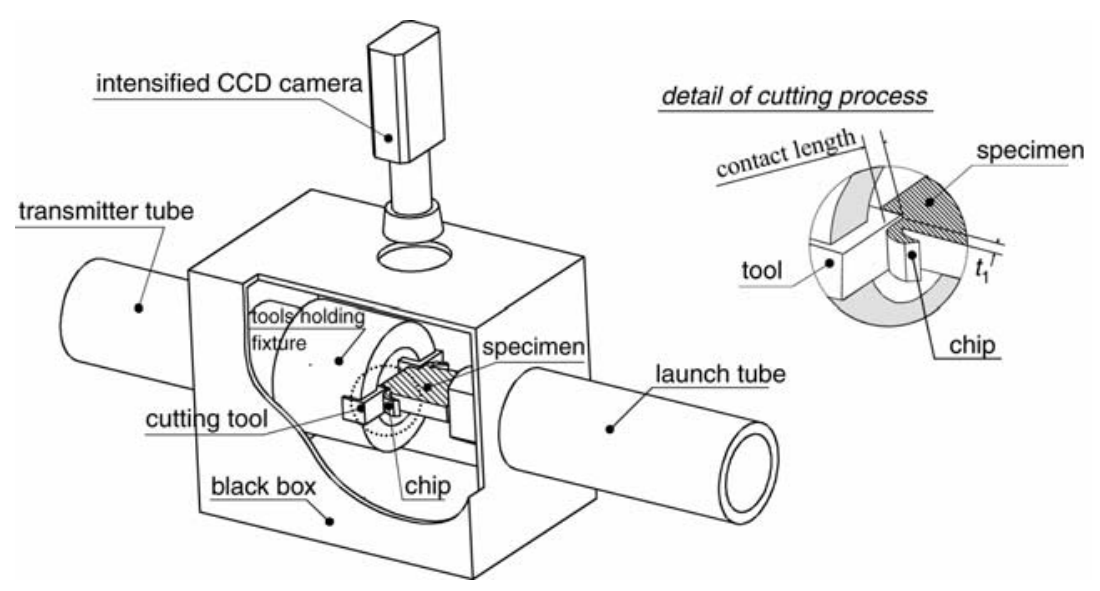

It is important to specify that, contrary to a real machining process, the time duration of tests is very short and varies from $100 \mu$ s to $1.2 \mathrm{~ms}$. Therefore, the wear and built up edge effect are negligible. In addition, although no thermal stationary condition can be reached in the tool, it is observed that quasi-stationary cutting conditions are reached in the chip after a short transient of few ten microseconds. Each cutting tests used a new carbide tool, without chip breaker and with a rake angle $0^{\circ}$.

A low carbon steel (XC18) cold drawn and an annealed medium carbon steel (42CrMo4) are used in the present tests. Their main mechanical characteristics are indicated in Table 1. 
Table 1 Mean mechanical properties of steels used in experiments

\begin{tabular}{lccccc}
\hline $\begin{array}{l}\text { Mechanical } \\
\text { properties }\end{array}$ & $\begin{array}{l}\text { Hardness } \\
{[\text { Brinell] }}\end{array}$ & $\begin{array}{l}\text { Yield stress } \\
{[\mathrm{MPa}]}\end{array}$ & $\begin{array}{l}\text { Ultimate tensile } \\
\text { strength }[\mathrm{MPa}]\end{array}$ & $\begin{array}{l}\text { Specific heat } \\
\text { capacity } \\
{\left[\mathrm{J} / \mathrm{Kg}^{\circ} \mathrm{K}\right]}\end{array}$ & $\begin{array}{l}\text { Thermal } \\
\text { conductivity } \\
{\left[\mathrm{W} / \mathrm{m}^{\circ} \mathrm{K}\right]}\end{array}$ \\
\hline $\mathrm{XC18}$ & 116 & 340 & 405 & $\approx 480$ & $\approx 52$ \\
$42 \mathrm{CrMo} 4$ & 241 & 485 & 814 & $470-560$ & $32-40$ \\
\hline
\end{tabular}

\subsection{Pyrometric measurements}

To measure the temperature field in the chip during the orthogonal cutting process, a broadband visible pyrometer was used. The choice of the visible spectral band enables us to reduce the error on the temperature measurement related to the uncertainties on the emissivity of the chip surface (Piriou, 1973). Indeed, we can show that the relative error on the temperature decreases when the wavelength of the optical radiation decreases (Ranc et al., 2004). Therefore, to measure the radiated power, we chose an intensified CCD camera whose spectral range is between 0.4 and $0.8 \mu \mathrm{m}$. The relative error between the real temperature and the radiance temperature is given in Ranc et al. (2004) versus the emissivity of the chip surface at a temperature of $800^{\circ} \mathrm{C}$ in the spectral band of the Intensified CCD. Bibliographical data (Touloukian and DeWitt, 1970) allows us to estimate that the order of magnitude of emissivity in the visible spectral range is 0.4 in the visible spectral band. The maximum relative error on temperature is then $5.3 \%$. A variation of $10 \%$ of the emissivity causes a relative error of $0.5 \%$ on temperature.

In this study, the aperture time varies between 64 and $600 \mu$ s. Only one image was carried out during a test because the refresh time of the CCD is much larger than the machining duration (about $300 \mu \mathrm{s}$ at $V=40 \mathrm{~m} / \mathrm{s}$.) To focus the maximum of the radiated energy, the intensified camera is coupled to an objective with a $50 \mathrm{~mm}$ focal length. This optical device allows to obtaining a very good spatial resolution: one pixel corresponds to approximately $3.6 \mu \mathrm{m}$ and the surface observed is a square of $3.7 \times 3.7 \mathrm{~mm}$. The calibration of the optical device and of the intensified camera is performed using a blackbody as a reference source.

A perfect synchronisation of the trigger mechanism with the recording system is required to obtain the image of the chip formation during the process (Sutter, 2005) Additional light sources are necessary and a very short exposure time $(\approx 1 \mathrm{~ms})$ is imposed to limit blur.

\section{Results and discussion}

Typical tool temperature maps obtained with our experimental set-up are presented in Figures 3 and 4, respectively for XC18 and 42CrMo4 steels. On these recordings, the heating up of the tool is not observed due to the very short time duration of the test. Consequently, the tool temperature is less than the minimum detected by the camera $\left(550^{\circ} \mathrm{C}\right)$. However, a rising of temperature can be observed on the machined workpiece surface, which is more pronounced with increasing cutting speed. 
To define the chip geometry, photographic recordings are taken during the process and are shown in Figure 5. For all tests, the chip is continuous for XC18 steel but segmented for $42 \mathrm{CrMo} 4$ steel. The segmentation creates thin areas between segments, which modify the rigidity of the chip. In addition, the chip has a complex trajectory when moving away from the tool rake face. Therefore, a given spatial position may be occupied by the chip at a given time and be exterior to the chip at a later time. At such a point, no stationary conditions are obtained, and the average temperature, measured over the aperture time of the camera (about $64 \mu \mathrm{s}$ ), has no easy physical interpretation.

Figure 3 Chip temperature maps during machining of XC18 steel (a) $V=23 \mathrm{~m} / \mathrm{s}, t_{1}=0.27 \mathrm{~mm}$; (b) $V=23 \mathrm{~m} / \mathrm{s}, t_{1}=0.38 \mathrm{~mm}$; (c) $V=38 \mathrm{~m} / \mathrm{s}, t_{1}=0.29 \mathrm{~mm}$ and (d) $V=38 \mathrm{~m} / \mathrm{s}$, $t_{1}=0.38 \mathrm{~mm}$

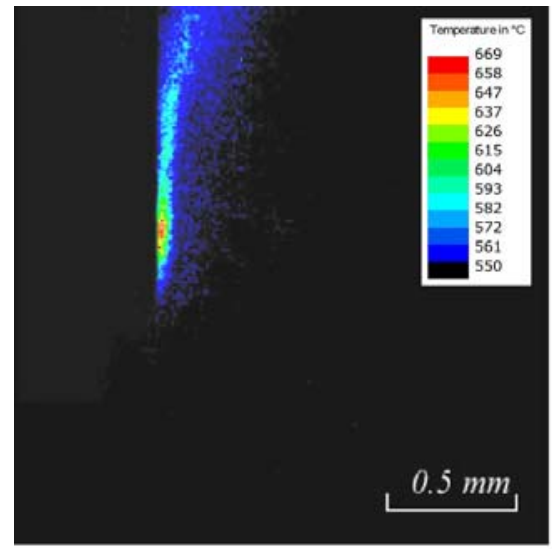

(a)

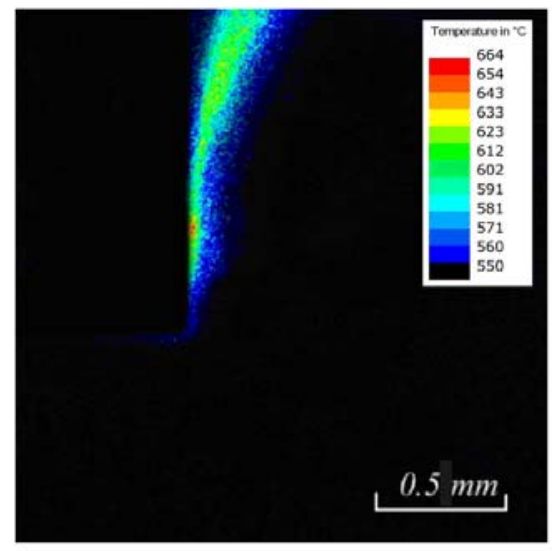

(c)

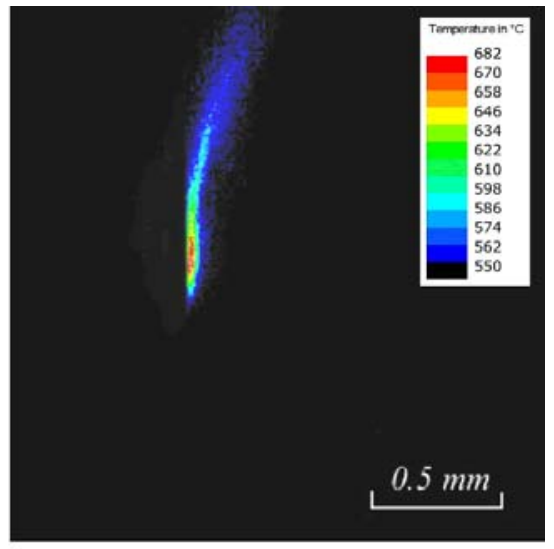

(b)

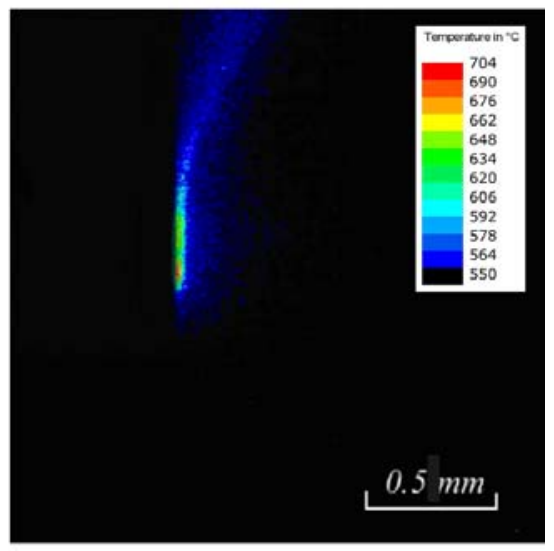

(d) 
Figure 4 Chip temperature maps during machining of $42 \mathrm{CrMo} 4$ steel (a) $V=18 \mathrm{~m} / \mathrm{s}$, $t_{1}=0.16 \mathrm{~mm}$; (b) $V=18 \mathrm{~m} / \mathrm{s}, t_{1}=0.28 \mathrm{~mm}$; (c) $V=22 \mathrm{~m} / \mathrm{s}, t_{1}=0.25 \mathrm{~mm}$ and (d) $V=38 \mathrm{~m} / \mathrm{s}, t_{l}=0.15 \mathrm{~mm}$

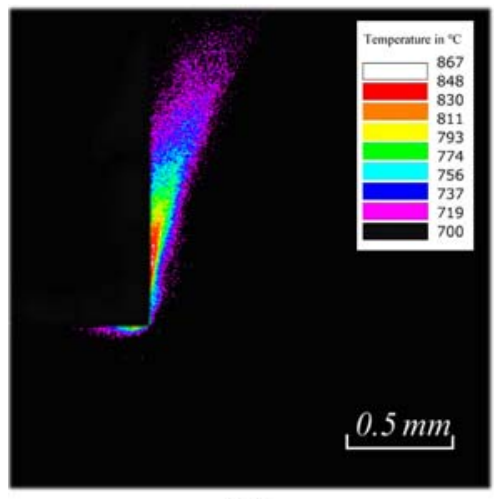

(a)

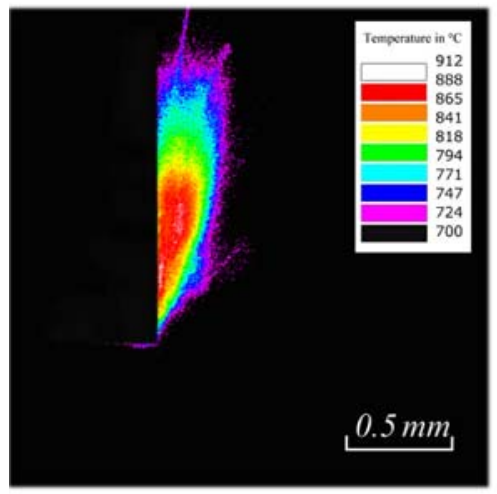

(c)

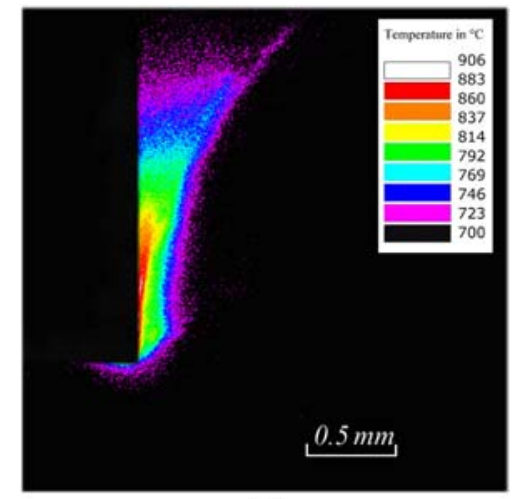

(b)

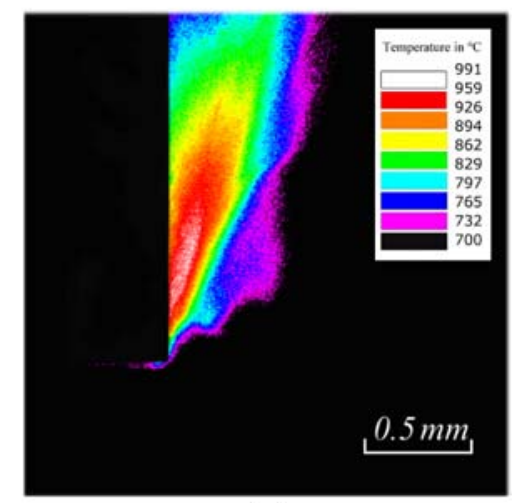

(d)

Figure 5 Real time photographs of chip formation (a) XC18 steel, $V=25 \mathrm{~m} / \mathrm{s}, t_{1}=0.27 \mathrm{~mm}$ and (b) $42 \mathrm{CrMo} 4$ steel, $V=17 \mathrm{~m} / \mathrm{s}, t_{1}=0.29 \mathrm{~mm}$

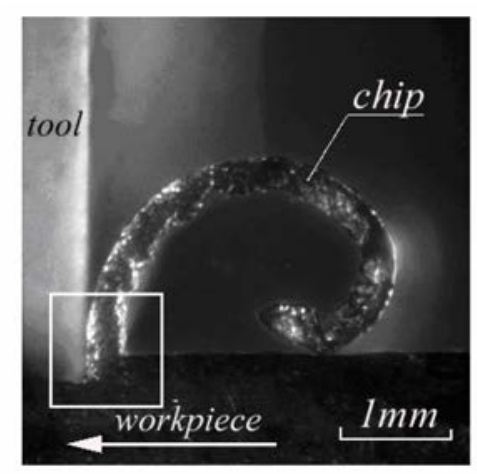

(a)

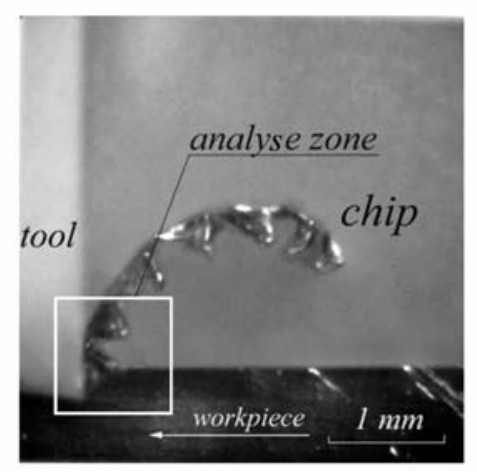

(b) 
On the contrary, in the chip domain close to the contact with the tool, represented by a white-bordered square in Figure 5, a quasi-stationary state is rapidly obtained and the temperature measurements can be interpreted. As seen in Figure 5, two chip geometries are obtained for about similar cutting conditions depending on the steel considered. The high optical and numerical resolutions of the temperature measurement set-up allow to characterise a local maximum of temperature near the tool chip interface. For XC18 steel, this maximum is at a distance about $0.8 t_{1}$ from the tool tip, where $t_{1}$ is the uncut chip thickness (see Figure 2). Close to the rake face, the heating of the chip is mainly due to the friction initiated at the tool tip and finishing at the end of the contact length.

Generally, higher temperatures are obtained for the $42 \mathrm{CrMo} 4$ steel as a consequence of the higher flow resistance of this material (cf. Table 1). Indeed, the initial heating of the chip at the outflow of the primary shear zone increases with the yield stress. In earlier investigations (Sutter et al., 2005), it was found that for similar cutting conditions, the tangential forces (parallel with the rake face) are greater for $42 \mathrm{CrMo} 4$ steel than for $\mathrm{XC18}$ steel and that the friction coefficient is reduced for the XC18 steel (Sutter et al., 2004) with respect to the $42 \mathrm{CrMo} 4$ steel.

Note that for the $42 \mathrm{CrMo} 4$ steel, two local maximums of temperature are found, the first $T_{\max 1}$ close to the contact area, the second $T_{\max 2}$ nearly outside the contact zone (see Figure 6). The existence of $T_{\max 1}$, as in XC18 steel, is related to the heating due to friction and plastic deformation. The second maximum observed in the 42crMo4 steel, might be related to plastic flow localisation leading to shear banding and chip segmentation, as observed in Figure 5(b). The maximum $\mathrm{T}_{\max 2}$ is not detected during the cut of the $\mathrm{XC18}$ steel, consistently with the fact that there is no shear banding in this material.

For the medium carbon steel 42CrMo4, first results (Sutter et al., 2003) obtained with previous generation camera show that the temperature measured (which was supposed to be $T_{\max }$ ) saturates with increasing cutting speed. It must be noted that during these previous works, the measurement point had a fixed position from the tool tip. However, the point where $T_{\max 1}$ is reached, is not a fixed location in the chip when the cutting velocity is changed. Therefore, further higher cutting speed experiments are needed to confirm the saturation of the temperature $T_{\max 1}$ with increasing cutting velocity.

Figure 6 Chip temperature maps of the analysed zone during machining (a) XC18 steel, $V=23 \mathrm{~m} / \mathrm{s}, t_{1}=0.38 \mathrm{~mm}$ and (b) $42 \mathrm{CrMo} 4$ steel, $V=18 \mathrm{~m} / \mathrm{s}, t_{1}=0.28 \mathrm{~mm}$

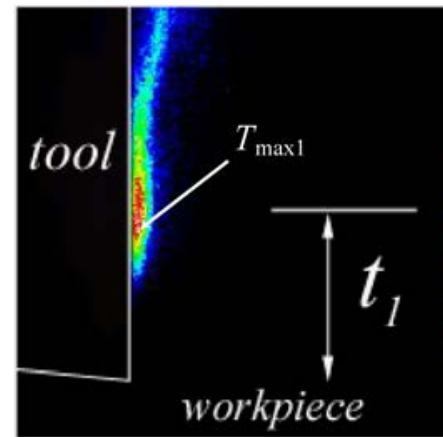

(a)

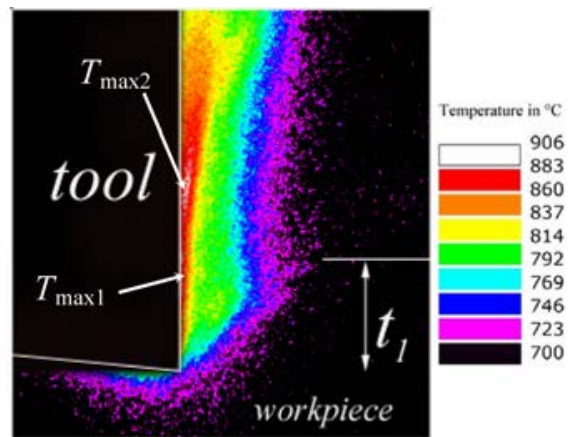

(b) 
In the present investigation, similar cutting conditions are realised for $\mathrm{XC1} 18$ steel and the point of maximum temperature is determined. Note that the measured temperature corresponds to a spatial averaging over a square of $10.8 \times 10.8 \mu \mathrm{m}$. The tests are performed for velocities varied from 20 to $65 \mathrm{~m} / \mathrm{s}$. Although an increasing temperature is observed with increasing cutting speed (see Figure 7), a saturation value does not seem to be attained in the range of velocities considered.

Figure 7 Effect of the cutting speed on the maximum temperature in the chip $\left(0.25 \mathrm{~mm} \geq t_{1} \geq 0.29 \mathrm{~mm}\right.$ and $0.34 \mathrm{~mm} \geq t_{1} \geq 0.38 \mathrm{~mm}, \alpha=0^{\circ}, \mathrm{XC} 18$ steel $)$

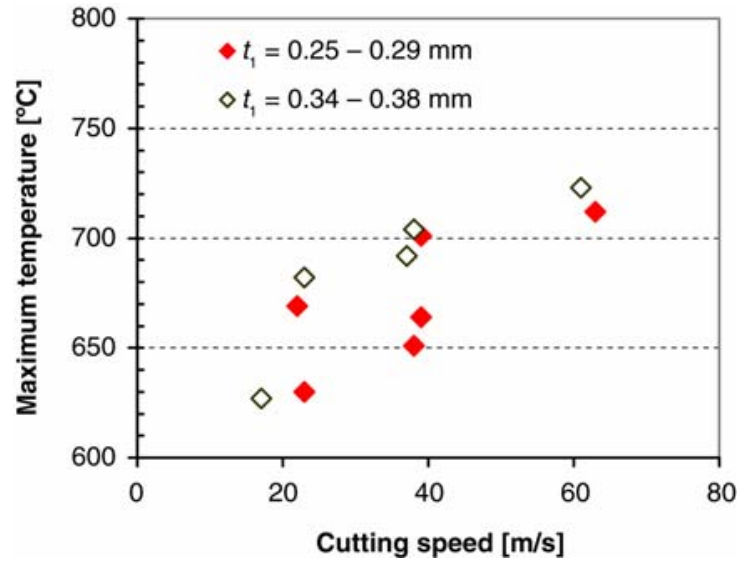

\section{Conclusions}

A ballistic experimental set-up allowing to reaching velocities up to $120 \mathrm{~m} / \mathrm{s}$ is used to study the effects of the cutting speed on the temperature field in the chip. A non-intrusive pyrometry technique is applied in the visible spectral band. Details of the tool-chip interface temperature can be observed with the high spatial resolution of the numerical camera coupled with high-performance optical device. Complementary information about chip formation, are given by high speed photograph techniques.

For a low and a medium carbon steel, temperatures maps recorded show that a local maximum of temperature is reached in a small area located very close to the tool-chip interface. This maximum temperature increases with the cutting speed. Tests undertaken at various cutting speeds and for different depths of cut seem to indicate that the temperature in the chip does not saturate in the range of cutting speeds explored here $(V<60 \mathrm{~m} / \mathrm{s})$. For the $42 \mathrm{crMo} 4$ steel, a second local maximum of temperature is found, which might be related to chip segmentation by shear banding.

\section{References}

Barrow, G. (1973) 'A review of experimental and theoretical techniques for assessing cutting temperature', Annals of the CIRP, Vol. 22, No. 2, pp.203-211.

El-Wardany, T.I., Mohamed E. and Elbestawi, M.A. (1996) 'Cutting temperature of ceramic tools in high speed machining of difficult-to-cut materials', International Journal of Machine Tools and Manufacture, Vol. 36, pp.611-634. 
Komanduri, R. and Hou, Z.B. (2001) "A review of the experimental techniques for the measurement of heat and temperature generated in some manufacturing processes and tribology', Tribology International, Vol. 34, pp.653-682.

Muller, B. and Renz, U. (2003) 'Time resolved temperature measurements in manufacturing', Measurement, Vol. 34, pp.363-370.

O'Sullivan, D. and Cotterell, M. (2001) 'Temperature measurement in single turning point', Journal of Materials Processing and Technology, Vol. 118, pp.301-308.

Outeiro, J.C., Dias, A.M. and Lebrun, J.L. (2004) 'Experimental assessment of temperature distribution in three-dimensional cutting process', Machining Science and Technology, Vol. 8, No. 3, pp.357-376.

Pina, V., Ranc, N., Wagner, D., Hervé, P., Sutter, G. and Philippon, S. (2004) 'Etude des comportements statique et dynamique de matériaux métalliques par pyrométrie ultraviolet, visible et infrarouge', Photoniques, Vol. 16, pp.42-45.

Piriou, B. (1973) 'Mise au point sur les facteurs d'émission', Revue Int. Htes Temp. Et Refract., Vol. 10, pp.283-295.

Ranc, N., Pina, V. and Hervé, P. (2000) 'Optical measurements of phase transition and temperature in adiabatic shear bands in titanium alloys', Journal of Physique IV France, Vol. 10, pp.347-352.

Ranc, N., Pina, V., Sutter, G. and Philippon, S. (2004) 'Temperature measurement by visible pyrometry - orthogonal cutting application', Journal of Heat Transfer, ASME, Vol. 126, pp.931-936.

Sutter, G. (2005) 'Chip geometries during high speed machining for orthogonal cutting conditions', International Journal of Machine Tools and Manufacture, Vol. 45, pp.719-726.

Sutter, G. and Molinari, A. (2005) 'Analysis of the cutting force components and friction in high speed machining', ASME Journal of Manufacturing Science and Engineering, Vol. 127, pp.245-250.

Sutter, G., Faure, L., Molinari, A., Ranc, N. and Pina, V. (2003) 'An experimental technique for the measurement of temperature fields for the orthogonal cutting in high speed', International Journal of Machines Tools and Manufacture, Vol. 43, pp.671-678.

Sutter, G., Philippon, S. and Molinari, A. (2004) 'An experimental investigation of dry friction for a large range of sliding velocities', Matériaux et Techniques, Vol. HS, pp.33-37.

Touloukian, Y.S. and DeWitt, D.P. (1970) Thermophysical Properties of Matter-Thermal Radiative Properties, New York, Washington: IFI/Plenum, Vol. 7. 